
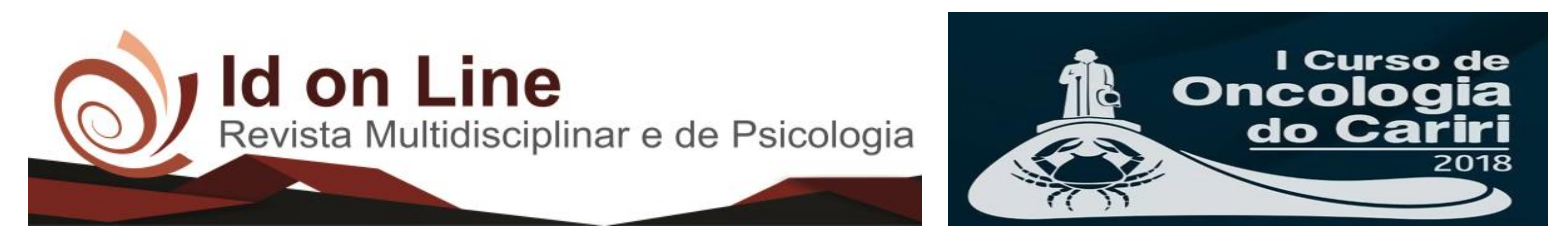

Resumo

\title{
ABORDAGENS TERAPÊUTICAS DOS TUMORES NEUROENDÓCRINOS GÁSTRICOS TIPO I
}

\author{
Cecília Gomes dos Santos Alves ${ }^{1}$, Sionara de Melo Figueiredo Carvalho ${ }^{1,2}$, Nélio Barreto Vieira ${ }^{1,2}$, \\ Modesto Leite Rolim Neto ${ }^{1,2}$, Jucier Gonçalves Júnior ${ }^{l}$
}

Introdução: A incidência de tumores neuroendócrinos (TNE) gástricos tem aumentado ao longo das últimas décadas, embora ela ainda seja menor quando nos referimos a outros órgãos gastrintestinais. Decorrente da hiperplasia das células enterocromafins em 1 a $2 \%$ de pacientes com gastrite atrófica, o TNE tipo 1 gástrico é o subtipo mais comum e representa 70 a $75 \%$ dos TNE gástricos. Devido à sua raridade, o número de estudos sobre as características clínica, patológica e prognóstica de TNE tem sido limitado, e estratégias terapêuticas ideais ainda não têm sido estabelecidas. Objetivo: revisão de literatura a partir da seguinte pergunta norteadora, quais as principais contribuições a literatura científica atual tem a oferecer acerca do tratamento do TNE gástricos tipo 1? Método: A busca foi realizada no período de 2000 a 2018 nas seguintes bases de dados online: Medical Literature Analysis and Retrieval System Online (MEDLINE), Literatura Latino-Americana e do Caribe em Ciências da Saúde (LILACS), Índice Bibliográfico Espanhol em Ciências da Saúde (IBECS) e Scientific Eletronic Library Online (SciELO). Utilizamos os descritores: "tumor neuroendócrino tipo 1" (DeCS); "Tratamento" (DeCS); e a "Abordagens terapêuticas" (palavra-chave). Resultados: a literatura recomenda ressecção endoscópica da lesão com endoscopia digestiva alta (EDA) seriadas como tratamento de eleição na maioria dos casos e suplementação de vitamina B12 $a$ posteriore. Quando há invasão profunda, metástases linfonodais ou nas lesões irressecáveis por endoscopia a cirurgia aberta é indicada. Entretanto, não há consenso na literatura sobre os casos de grande número de lesões ou recidivas frequentes. O tipo cirúrgico também é controverso, só tornando-se claro que a gastrectomia subtotal ou total são opções mais adequadas que a antrectomia, pois, a redução das células $G$ não implica necessariamente na redução da produção de ácido clorídricos pelas enterocromafins like que podem tornar-se autônomas. A linfadectomia deve ser realizado se indícios de doenças extra gástrica ou fatores de mal prognóstico. Não há dados que apoiem tratamento adjuvante nesses pacientes. Conclusão: ressecção endoscópica seguida de suplementação de vitamina B12 na maioria dos casos é o método terapêutico de escolha, naqueles pacientes com contra indicação a gastrectomia subtotal ou total parece o método mais adequado. Entretanto, ressalta-se a necessidade de estudos com maior nível de evidência.

Palavras-chave: Tumores gástricos; Tumor neuroendócrino tipo 1; Tratamento; Revisão de literatura

\footnotetext{
${ }^{1}$ Faculdade de Medicina, Universidade Federal do Cariri, Barbalha, Ceará, Brasil.

${ }^{2}$ Programa de Pós-Graduação em Ciências da Saúde, Faculdade de Medicina do ABC (FMABC), Santo André, São Paulo, Brasil.

Autor Correspondente: ceciliagomes.sa@gmail.com.
}

13 Id on Line Rev. Mult. Psic. V.12, N. 40. 2018 - ISSN 1981-1179 EDIÇÃO ESPECIAL: I CURSO DE ONCOLOGIA DO CARIRI / II JORNADA DE PESQUISA QUANTI-QUALITATIVA EM ONCOLOGIA. JUAZEIRO DO NORTE, 05 A 10 DE MARÇO DE 2018. Edição eletrônica em http://idonline.emnuvens.com.br/id 